\title{
Returns to education, productivity, and economic growth in China
}

\author{
Qinghua Zhang (Guanghua School of Management, Peking University) \\ Heng-Fu Zou (Peking University, World Bank)
}

\begin{abstract}
This paper surveys the literature on the return to education and economic growth in China and offers new perspectives and estimations. The return to education has been rising since the reform. While the overall rate of return is still low compared to other countries, young workers and workers in the private sector enjoy significantly higher returns to education than the average. This indicates that the productivity-related traits such as education are more rewarded where market forces are functioning. Moreover, the return to education is non-linear in the sense that the return to secondary education or above is much higher. In addition, due to the spatial segmentation of labor markets in China, wide variations in return to education exist across regions. Studies at the macro-level show that the return to public education is much higher than return to private education. Using recent data (1982-2001) across provinces, this paper examines how education contributes to China's economic growth. It finds that the increase in educational attainment plays an important role in China's economic growth as well as the initial level of educational attainment.
\end{abstract}

See http://www.tandfonline.com/doi/abs/10.1080/13876980701494707 